\title{
Walking worker vs fixed worker assembly considering the impact of components exposure on assembly time and energy expenditure
}

\author{
Martina Calzavara $^{1} \cdot$ Maurizio Faccio $^{1} \cdot$ Alessandro Persona $^{1} \cdot$ Ilenia Zennaro ${ }^{1}$
}

Received: 30 July 2020 / Accepted: 1 December 2020 / Published online: 11 January 2021

(C) The Author(s) 2021

\begin{abstract}
Recently, the need for assembly systems of better following the market demand has led to the spread of alternative solutions with respect to the traditional fixed worker strategy. Walking worker systems, where operators move across the line to produce the finished product, are gaining always more interest. In this paper, a comparison between the fixed worker $(\mathrm{FW})$ and the walking worker (WW) assembly strategies is provided, by taking into account their differences both in terms of performed activities during assembly and of material exposure at the assembly workstations. The evaluation is carried out through the proposal of a mathematical model, to understand the impact on assembly time and on operators' energy expenditure. The behavior of the model is investigated both with a parametric analysis and a real case study. The results show that the FW is the best one when the system is working at its maximum throughput, while the WW strategy turns out to be preferable for the lower values of market demand, both from a time and an energy expenditure perspective.
\end{abstract}

Keywords Assembly $\cdot$ Walking worker $\cdot$ Fixed worker $\cdot$ Comparison model $\cdot$ Energy expenditure

\section{Introduction}

The current demands of the market are characterized by the increase of products' personalization and by the reduction of the life cycle of the products. This fluctuating nature of market demands has forced manufacturing firms to develop alternative production systems capable of responding quickly and economically to such unpredictable circumstances. Therefore, in recent years, it has become increasingly important to develop efficient, but also flexible and reconfigurable production processes and systems [1]. A significant proportion of manufacturing processes and costs are dedicated to the process of product assembly. In fact, approximately $40 \%$ of the product cost is in the assembly stage [2]. Despite the trend towards implementing automated production systems, especially in Western countries, where the labor cost is high, there is still a significant and justifiable need for manual assembly [3]. According to [4], the assembly systems can be classified following some design

Maurizio Faccio

maurizio.faccio@unipd.it

1 Department of Management and Engineering, University of Padova, Stradella San Nicola 3, 36100 Vicenza, Italy principles and selection criteria, based on flexibility, batch size, production volume, and number: dedicated (automated) assembly systems, flexible (automated) assembly systems, and manual assembly systems. From their classification, it is clear how manual assembly is able to face the highest flexibility level, even with the highest level of product variants, low production volume, and batch size equal to 1 . Due to the high requirement of flexibility, manual assembly is the most used assembly technology in the modern manufacturing systems. Manual operations are used in the assembly of complex work elements as well as when production demand is unstable or where the use of specialized machines and equipment is unjustifiably expensive. Flexibility requirement is more evident in assembly because it is typically the last production process. As reported by [5], the basic requirements in terms of flexibility can be summarized as:

- mix flexibility, i.e., the ability to handle a wide variety of part types (components), and manage a wide mix of components and products;

- volume flexibility, i.e., the ability to change the productivity of the system without reducing the efficiency of the system;

- layout flexibility, i.e., the ability to change the production resource disposition, number, and assigned tasks as the effect of mix and volume flexibility permitting quick 
market response, using adaptive flexible production systems [6].

A traditional manual assembly line is characterized by the presence of one worker in each workstation, who performs the assembly, while the assembled components (also called parts) are transported from one workstation to another by a handling system. This type of assembly line is called a fixed worker (FW) assembly line, where the assembly worker always remains in the same workstation, to perform a single and often repetitive set of assembling tasks [7] (Fig. 1 left side). Considering volume flexibility in FW assembly systems, caution must be exercised [8]. In fact, this requires adjusting the number of workers in the line according to the changes of the production demand (assembly line balancing). The assembly line re-balancing as a function of the production volume fluctuation implies, among other things, to change the number of assembly stations, their position, the components and tools assignment to each station, and, at last, the assembly line layout modification. From this perspective, a FW assembly system can reach a good level of mix flexibility if configured as a mixed model one [9], but presents low levels of volume and layout flexibility. If the number of workers equals the number of workstations and it remains constant, there will be a waste of production capacity if the production volume is reduced [1]. Finally, in the FW configuration, the production rate of the line is determined by the workstation with the longest process time.

An alternative approach is the so-called walking worker (WW) assembly line, where the worker travels along the line carrying out all assembly tasks in all workstations [10]. A typical WW assembly line is configured in a U-shape layout in order to reduce the walking distance from the last and the first assembly station. Walking worker (WW) assembly lines differ from the traditional linear FW assembly lines because the workers are cross-trained, so that each one is able to fully assemble the product from beginning to end. In this case, the number of walking operators is minus or equal to the number of stations. Figure 1 (right side) reports a case with 5 stations and 3 operators. [11] showed how the application of this system in production lines has enabled to achieve easier line balancing, to reduce the number of buffers required, to reach greater variations in the work time and a better adjustable number of line workers according to demand requirements. In other words, WW can achieve, if compared with the traditional FW, a greater level of production volume flexibility without changing the assembly system layout, parts disposition, tools disposition, parts logistics, etc., guaranteeing, in this sense, the layout flexibility. Table 1 shows (in black) a comparison between the two types ( $\mathrm{FW}$ and WW) derived by [1], while (in blue) an extension made by the authors.

In terms of total assembly times, the WW system suffers from the movement time of the operators, which is added to the assembly cycle time, consequently reducing the throughput. This movement influences also the operators' energy expenditure during the assembly.

On the other hand, there is an opposite effect, related to the storage locations (SLs) of the components to assemble and to their exposure within the workstations. Each assembly activity can be considered as the sum of two main operations: the component picking and the task execution (e.g., component fastening) [12-14] highlight that the material exposure to the assembly operator strongly impacts on the components picking time that can represent even a large portion of the total assembly time. Indeed, the picking time is affected by the component storage location in the station with respect to the worker and to the assembly workspace. The picking time can be significantly decreased by optimizing the component storage strategy at the station level. On the other hand, the number of components that can be located in the best storage locations in terms of picking time is constrained by the assembly station dimension [12]. Figure 2, derived by [12], graphically

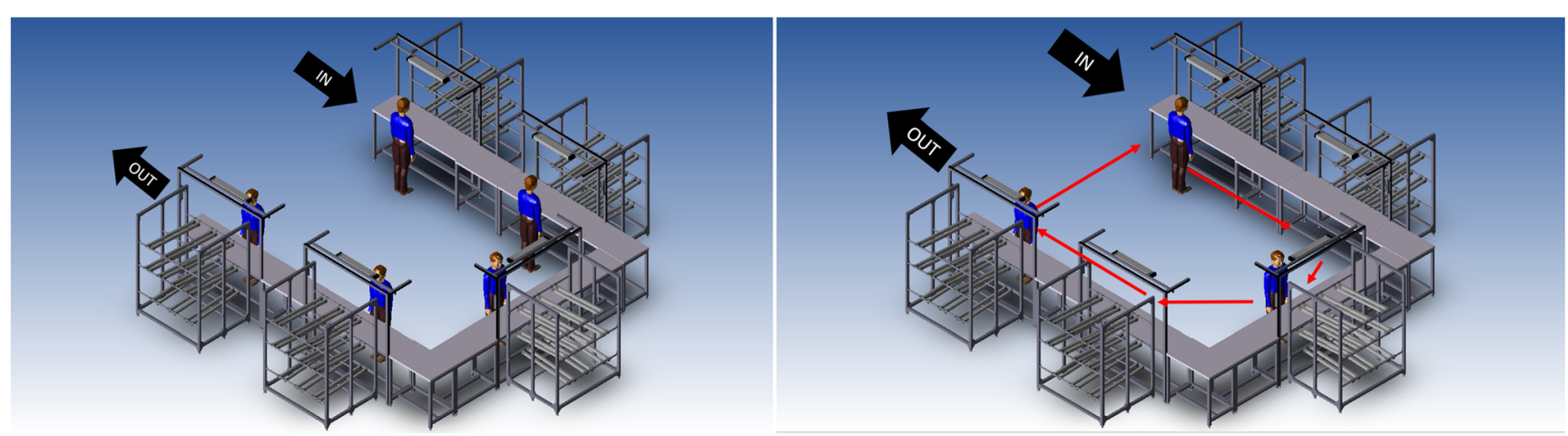

Fig. 1 Example of a FW system with 5 stations and 5 operators (left) and a WW system with 5 stations and 3 operators (right) 
Table 1 FW-WW comparison. Extension of table 1 of [1] in italics and extended by the authors (in bold)

\begin{tabular}{|c|c|c|}
\hline Indicator & FW-fixed worker & WW-walking worker \\
\hline $\begin{array}{l}\text { Number of } \\
\text { stations vs } \\
\text { number of } \\
\text { operator }\end{array}$ & Number of workers $=$ number of workstations & Number of workers $\leq$ number of workstations \\
\hline Mix flexibility & High (mixed model assembly system) & High (mixed model assembly system) \\
\hline Volume flexibility & Low (due to the re-balancing problem) & $\begin{array}{l}\text { High (thanks to the independence from the re-balancing } \\
\text { problem) }\end{array}$ \\
\hline Layout flexibility & $\begin{array}{l}\text { Low (due to the variation of the number of workstations } \\
\text { because of the re-balancing, with effects on space } \\
\text { utilization, materials, and tools location) }\end{array}$ & $\begin{array}{l}\text { High (thanks to the independence from the re-balancing } \\
\text { problem) }\end{array}$ \\
\hline Labor utilization & $\begin{array}{l}\text { High when the target production volume is equal to the } \\
\text { maximum assembly line throughput, low otherwise }\end{array}$ & $\begin{array}{l}\text { High if the number of workers is optimized as consequence } \\
\text { of the target production volume }\end{array}$ \\
\hline Labor skills & Low skills & Cross-training of workers \\
\hline Efficiency & $\begin{array}{l}\text { High if the number of workstations equal to the number of } \\
\text { workers is re-defined as consequence of the target pro- } \\
\text { duction volume }\end{array}$ & $\begin{array}{l}\text { High if the number of workers is optimized as consequence } \\
\text { of the target production volume }\end{array}$ \\
\hline Balancing & Poor tolerance to variations in line balance & Better tolerance of work time variations \\
\hline $\begin{array}{l}\text { Storage locations } \\
\text { (SLs) of the } \\
\text { components }\end{array}$ & $\begin{array}{l}\text { The location of the components is affected by the change in } \\
\text { the number of workstations. As this decreases, the average } \\
\text { number of components per station increases. } \\
\text { Consequently, they are located in farther and less } \\
\text { ergonomic positions }\end{array}$ & $\begin{array}{l}\text { The location of the components is not affected by the change } \\
\text { in the number of workstations. The average number of } \\
\text { components per station remains the minimum (the same } \\
\text { of the one of the maximum productivity of the line). } \\
\text { Consequently, their locations are always in the best } \\
\text { possible ones. }\end{array}$ \\
\hline Task time & $\begin{array}{l}\text { Task time is influenced by the component picking and } \\
\text { placing times, i.e., by the location of the components } \\
\text { within the workspace. The reduction of the number of } \\
\text { assembly workstations, due to the reduction of the } \\
\text { production volume, increases the task time }\end{array}$ & $\begin{array}{l}\text { Task time is influenced by the part picking and placing times } \\
\text { and by the travel time along the line. Since the number of } \\
\text { workstations does not change, task time is the same in all } \\
\text { the production volume configurations. }\end{array}$ \\
\hline $\begin{array}{l}\text { Ergonomic } \\
\text { conditions }\end{array}$ & $\begin{array}{l}\text { Probability of musculoskeletal symptoms increases because of } \\
\text { single and repetitive tasks performed by static worker. } \\
\text { Moreover, picking from some storage locations could be } \\
\text { critical in case of a higher number of components per } \\
\text { station }\end{array}$ & $\begin{array}{l}\text { Worker walks during the work with a reduction of the risk of } \\
\text { repetitive injuries. Moreover, the picking activities are } \\
\text { always the same also when the number of workers } \\
\text { changes }\end{array}$ \\
\hline $\begin{array}{l}\text { Energy } \\
\text { expenditure }\end{array}$ & $\begin{array}{l}\text { The reduction of the number of assembly workstations, due } \\
\text { to the reduction of the production volume, increases the } \\
\text { workers energy expenditure }\end{array}$ & $\begin{array}{l}\text { The workers' energy expenditure is affected by the traveling } \\
\text { activity during the assembly }\end{array}$ \\
\hline
\end{tabular}

represents the typical SLs with respect to an assembly workspace and proposes the top view of a typical manual assembly station with the most relevant geometrical dimensions. The estimated component picking time significantly decreases from the last to the most accessible SLs. Since the WW assembly system maintains the maximum number of assembly stations, even when the target productivity decreases, the possibility of placing the components in the best
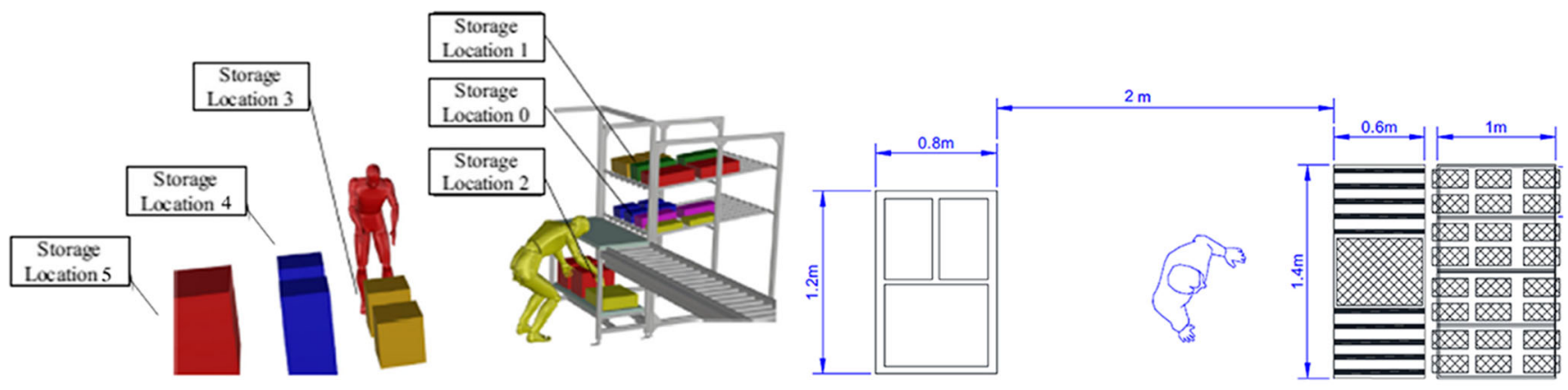

Top View

Fig. 2 Storage locations' (SLs) position and dimension in a typical manual assembly station, including potential SL4 and SL 5 [12] 
SLs (i.e., SL0 and SL1) is not affected by the production volume reduction. On the other hand, considering the FW assembly system, a decrease of the target productivity of the system generally implies a reduction of the number of stations, a new assembly line balancing, and a new layout definition.

This reduction of assembly stations has a negative impact on the total assembly time, since the available space for placing parts in the best SLs is reduced and a larger number of components will be placed in farther SLs, increasing the picking times. In the same way, the operator energy expenditure in case of WW is not affected by the production volume reduction, while in case of $\mathrm{FW}$, the energy expenditure will increase when the number of the assembly station decreases, due to greater movements during the picking activity (Fig. 2).

There is a trade-off between the operators' movement time and the operators' picking time as a function of the stations' number and of the production volume variations. As also reported in the following literature review, the lack of quantitative comparison approaches in this field that takes into account these factors is evident. In fact, even if the WW assembly lines are widely adopted in manufacturing for their benefits, they have not been enough studied so far, especially if compared with the traditional FW systems. The basic motivation of this research arises from the study of the impact of material exposure to the operators on the performances of the FW and WW systems. Since the key element for WW is the production volume flexibility and the related assembly systems layout flexibility, this study compares the WW and the FW as a function of the fluctuation of the target throughput. Moreover, two basic comparison functions between the two assembly systems are considered: the total assembly time and the total operators' energy expenditure. The paper proposes an original mathematical comparison model that, starting from the assembly system design and balancing, calculates the system total assembly time and the total energy expenditure considering the potential storage locations of the components and the related constraints at the assembly station in terms of number of storable components (Fig. 2). For this purpose, the related picking times and energy expenditures are considered, as well as the operators' travel times and energy expenditures. Moreover, a parametric study considering different assembly scenarios has been developed, in order to validate the proposed comparison model and to generalize the results by defining a set of best practices to use for practitioners. Finally, a case study from an Italian pumps manufacturer is reported, exemplifying the applicability and the practical implications of the research.

The remainder of this paper is organized as follows. Section 2 presents the literature review on FW and WW systems and on assembly systems design considering ergonomic factors. Then, Section 3 introduces the definition of the problem and the mathematical model for the comparison of the two systems, which has been applied to a parametric analysis in
Section 4. Section 5 summarizes the evidence of the case study, while Section 6 reports the conclusions and further researches.

\section{Literature review}

Assembly system design is an interesting operations management research problem since assembly line balancing (ALB) was first introduced by [15]. Considering this problem complexity, several authors proposed different versions of the ALB, typically focusing on one or more specific features of the analyzed assembly system. [16] suggest how a relevant number of researchers tackled the ALB considering the same recurrent features and classify an assembly system according to the assembly station or the line layout, the stochastic or deterministic assembly times, the buffer presence, and the targeted objective functions and the selected solving methods. Even if the number of contributions on assembly systems design and balancing is huge, the research on walking worker assembly systems is poor and relatively young. In fact, some first concepts on a U-shape layout with the possibility for workers to move across the line were presented in early studies within a lean production [17-19], as a possible approach to reach flexibility in the future state value stream mapping. The term "WW assembly line" is a recent concept [20], and only in the mid-2000s, it is possible to find the first researches on WW with the studies of [7] on linear rabbit chase walking worker assembly lines and [21] on the bucket brigade-based WW assembly lines. Indeed, the WW system, with the possibility to have moving operators across the assembly stations, presents different variants (with potential sub-variants):

- "Rabbit Chase," where the operators walk between the workstations, arranged in the desired configuration (typically U-shaped), to carry out the set of tasks assigned in each workstation. Therefore, in this type of assembly line, each worker travels the entire line, moving from one location to another, together with the product to be assembled to perform all the required tasks [7].

- "Bucket Brigades," where each worker carries out the work on one piece from one station to another until another worker resumes his work; then, this worker returns to take the job from his predecessor [21]. When the last worker finishes the work on the product, he goes back to resume the work of his predecessor, who goes back and resumes the work of his predecessor and so on, until, after having transferred the product he was working on to his successor, the first worker returns to the beginning of the line to start a new product.

- "Baton Touch," where the products to be assembled are processed one at a time, by multi-functional operators who walk between the various positions assigned to them. Usually, each operator has to manage multiple stations, 
not necessarily consecutive. A floating worker supervises both the entry and the exit of the line [22].

Table 2 reports a basic literature review on WW assembly systems. Looking at Table 2, it is possible to affirm that the studies primarily consider single-model traditional WW system (rabbit chase), with both $U$ and straight layouts, with deterministic task times and where the basic applied methods are simulation and mathematical models. On the other hand, some studies are introducing multi and mixed-model assembly systems and stochastic task times. From the objectives point of view, the contributions are here classified as follows:

- WW vs FW system analysis. [7], in one of the first related researches, propose a comparison between WWAL and FWAL in terms of performance measures. [23], considering a real case, illustrate the transition process from $\mathrm{FW}$ to WW. [24] consider the use of simulation in verification of a mathematical model for predicting the performance of manual assembly line occupied with flexible workforce.

- WW system analysis and optimization. [25] identify the levels of process parameters that entail the improvements on both productivity and ergonomics. Other studies of the same authors develop mathematical models considering the structural variables of WW for its optimization, with stochastic task times [26] and a mixed model production [27, $28]$ illustrate the influence of workers' variability and different patterns of imbalances in output, while [29] provides a work-sharing protocol that considers discrete tasks and worker crossovers. At last, considering the impact of task time variation and models variation, [30] investigate the effects of sources of randomness on model validation as an abstraction for the real system, while [31] addresses the balancing problem for multi-model WW assembly systems.

- WW Bucket Brigade system analysis and optimization. All the studies are here focused on the balancing of the workload between the WW. [21] extend the standard model of bucket brigades to capture hand-off and walkback times, while [32] analyze the convergence conditions for a bucket brigade. [33] analyze the self-balancing for a finite backward velocity and [34] study the dynamics of 2worker $\mathrm{m}$-stations bucket brigade assembly lines.

- WW waiting time and travel time analysis and optimization. [35] examine the variable behavior of the in-process waiting time, while $[36,37]$ evaluate the critical factor of in-progress waiting time and mathematically analyze the varying magnitude of production loss.

- WW number of operators/stations analysis and optimization. [38] observe the interrelationships between the number of workstations and the number of walking workers for their minimization, while [39] proposes a methodology for minimizing number of workers and smoothing workload among stations, and [40] analyze multi-manned assembly with walking workers for minimizing the number of workers and workstations.

- WW and lean principles analysis. [41] investigates the lean principles applied into a real-life WW assembly system, while [42] incorporate $5 \mathrm{~S}$ management rules into WW assembly system design as a combination of lean management approaches. [43] propose a framework for the modeling and optimization of a lean assembly system design with multiple objectives.

Although many of the reported contributions on WW systems highlight the interesting applicability and the benefits of such systems, none of them focuses on the investigation of ergonomic aspects. However, these can represent a distinctive feature, especially when it has to be chosen the system to use (for example $\mathrm{FW}$ or WW) for a certain assembly process [24]. The consideration of ergonomics during assembly line design usually allows taking into account both the impact of the assembly tasks and the components picking [46, 47]. Related to this, some researches have proposed assembly line design methods and balancing approaches considering ergonomics from various points of view.

One of the first contributions related to ergonomics and assembly line balancing is by [48]; in their paper, they propose to include the physical demands of each task and related physical constraints in assembly line balancing. In the same direction, [49] introduce three-line balancing heuristics that incorporate physical demands of the assembly tasks: a ranking heuristic, a combinatorial genetic algorithm, and a problem space genetic algorithm. [50] investigate the possibility of including ergonomic risks estimation in assembly line balancing, showing that this requires a low additional computational cost, and that in many cases, it leads to the need of introducing additional workstations to reduce the physical effort of the operators. More recently, [51, 52] aim at minimizing the maximum ergonomic risk by including physical factors in line balancing through RULA, OCRA, and NIOSH assessment methods. [53] develop a multi-objective model by including the energy expenditure of the tasks through the so-called predetermined motion energy system, which allows to easily estimate the energy expenditure of the most common activities that are performed during an assembly process. Similarly, [54] introduce a multi-objective genetic algorithm for assembly line balancing taking into account ergonomics through energy expenditure, while [55] focus on U-shaped assembly lines and an ergonomic risk evaluated through OCRA index.

As far as materials exposure and picking in an assembly system are concerned, the contributions taking into account also ergonomics are not many. [56] study the impact of movements, postures, and forces in picking components in two alternative kitting configurations, picker-to-material, and material-to-picker. $[57,58]$ highlight the impact of box and 


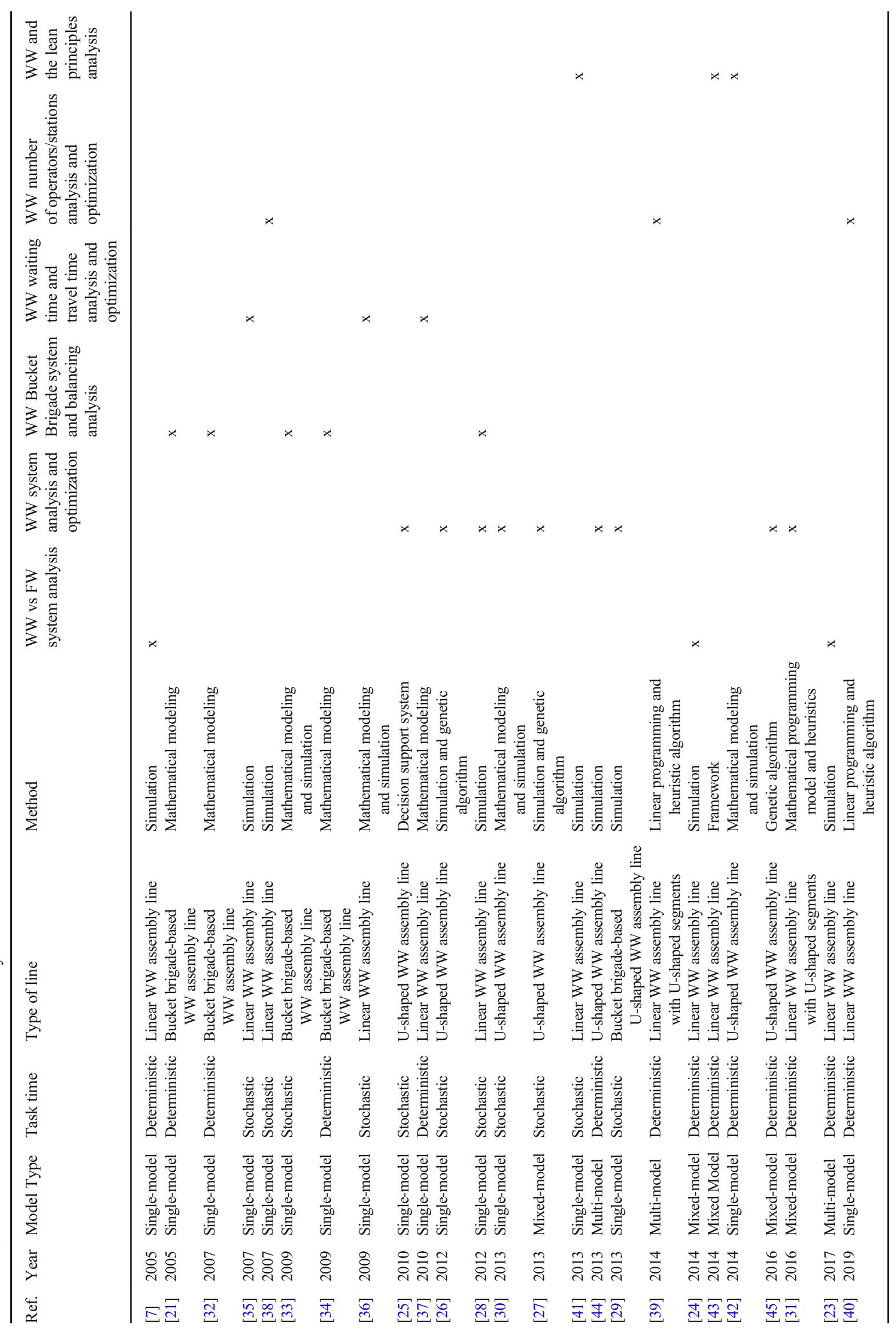


components characteristics and of workplace layout on the ergonomic risks of components picking. While the first one refers to the maximum acceptable weights (MAWs), the second one uses the biomechanical loading on operators' spine and shoulder. [59] evaluate components' picking activities from unit loads (pallets) and from boxes stored on racks by measuring times and OWAS indexes. On the other side, [60, 61] focus on measuring time and physical workload only on large containers. Generally, the results of all these studies show a substantial impact of materials exposure on picking time and ergonomic risks, with lower times and better ergonomic levels when the material is stored close to the operator and at a proper height [62].

Considering the impact of ergonomics both on assembly line balancing and on parts feeding and exposure, recent researches propose to model it with an integrated perspective. $[47,63]$ develop an integrated assembly line balancing problem considering the energy expenditure of assembly and components picking, while [12] propose to evaluate the same aspects by using REBA method. On the other side, [64, 65] consider ergonomics for both assembly line design and balancing, focusing on single- and mixed-model assembly lines. As it can be seen from the literature review here presented, there are few approaches that consider the impact of materials' exposure and components picking on assembly times and operators' ergonomics. Moreover, the existing contributions refer to standard fixed worker assembly systems. Therefore, the present paper aims at covering this research gap, by introducing a method to compare the impact of assembly system design on the performances of FW and WW assembly systems. In particular, it allows to evaluate how material exposure influence total assembly time and total operators' energy expenditure, as shown in the following sections.

\section{Mathematical model for FW and WW comparison}

The aim of this paper is to propose an original mathematical comparison model that, starting from the assembly system design and balancing, calculates the system total assembly time and the total energy expenditure considering the potential storage locations of the components and the related constraints at the assembly station in terms of number of storable components (Fig. 2).

The design process of an assembly system is typically based on the maximum market demand that has to be satisfied [66], which determines the maximum system throughput $Q_{\text {target }}$ and, then, the maximum number of assembly workstations $(K)$ and of operators $\left(N_{o p}\right)$. In case of maximum system throughput, the two systems have the same number of workstations and of operators, and also, the assignment of the tasks to the workstations (line balancing) is the same. However, since FW and WW systems are considered to operate with a JIT approach if the throughput decreases, they have to be resized accordingly. In FW systems, since there is one fixed operator for each workstation, the re-sizing requires the decrease of the number of workstations as well as of the number of operators. Moreover, it is also needed to re-balance the line with the new number of workstations. On the other side, in WW systems, the number of workstations remains the same (and it is always equal to the maximum number $K$ ) while only the number of operators decreases according to the system throughput. Therefore, it is not needed to re-balance the line.

\subsection{Assumptions and notations}

FW and WW systems are compared in terms of flexibility, productivity, and energy expenditure; the model is based on the following assumptions, which can be easily applied to different contexts:

1. The systems realize one single product (simple assembly line balancing problem, SALBP)

2. The system has a continuous products flow (there are no buffers)

3. The product moves between the workstations with an automatic handling system

4. The considered WW system is the Rabbit Chase case (RC)

5. The FW system has a linear layout while the WW system has a U-shaped layout

6. The distance between workstations is fixed and equal for all workstations

7. The workstation size and the storage locations (SLs) are the ones proposed by [12]

8. Each task refers to one component to assemble and each component is assigned to only one task

9. Each task includes one single picking activity and one assembly activity

10. All activities times are deterministic

11. Failures time, waiting time, and set-up time are not considered in the problem

12. Workers are male operators, all with the same skill level

13. All workers are able to carry out all tasks in both configurations

14. Workers' walking speed is constant

15. The effect of fatigue on tasks' execution performance is not considered

16. Since the considered components' weights are standard, these do not affect the picking time but only the picking energy expenditure [12]

17. The initial number of workers and workstations is the same in both configurations (FW and WW)

18. The changes of the system throughput are proportional to $Q_{\text {target }} / K$ and directly related to these 
values (i.e., the considered line configurations are related to the various maximum number of workstations)

19. Re-layout costs and re-balancing costs of the FW system are not considered in case of changes in productivity.

Moreover, workers' tasks can be classified into three categories:

- Assembly activity related to the execution of the task in the workstation; both the duration and the energy expenditure of this activity are known.

- Picking activity of the component needed for the execution of the task; the time and the energy expenditure of this activity are related to the storage location (SL) of the component that varies according to the considered configuration.

- Travel activity between workstations (just in the WW system); the duration and the energy expenditure of this activity depend on the distance between the workstations and on the worker's speed.
Table 3 presents the main variables and the notations of the model.

\subsection{FW-WW balancing and comparison model}

The comparison of the two systems is carried out by a mathematical model with an objective function that considers the maximum workload of the assembly line. The comparison requires the application of three subsequent steps:

1. Define the design of the assembly line

2. Balance the assembly line, minimizing the objective function under the specified constraints

3. Calculate the comparison parameters

\subsubsection{Assembly line design}

As first, the design of the two configurations is carried out, by defining the number of workstations $(K)$ and of required operators $\left(N_{o p}\right)$. In both cases, the assembly lines are sized based

Table 3 Notations

\begin{tabular}{|c|c|c|}
\hline Notation & Description & Unit \\
\hline$j$ & $=1 \ldots n$ assembly tasks index & - \\
\hline$k$ & $=1 \ldots K$ workstations index & - \\
\hline$w$ & $=0 \ldots \mathrm{W}$ SLs index & - \\
\hline K & Maximum number of workstations & - \\
\hline$K^{F W}$ & Number of workstations for FW when $\mathrm{Q}<$ Qtarget $\left(K^{F W}<K\right)$ & - \\
\hline$D$ & Average distance between two workstations & $\mathrm{m}$ \\
\hline$C_{w k}$ & Maximum capacity of SL $w$ for workstation $k$ & $m^{3}$ \\
\hline$Q_{\text {target }}$ & Maximum target throughput of the system & $\mathrm{pieces} / \mathrm{min}$ \\
\hline$P V$ & Production volume flexibility parameter & $\%$ \\
\hline$N_{o p}$ & Total number of operators & - \\
\hline$v$ & Operator walking speed & $\mathrm{m} / \mathrm{s}$ \\
\hline$L_{j}$ & Weight of component of task $j$ & $\mathrm{~kg}$ \\
\hline $\bar{L}$ & Average of the weights of all components, $\bar{L}=\sum_{j=1}^{n} L_{j} / n$ & $\mathrm{~kg}$ \\
\hline$t_{j}$ & Assembly time of task $j$ & s/piece \\
\hline$t_{p, w}$ & Picking time from SL $w$ & s/piece \\
\hline$A T_{k}$ & Assembly time in workstation $k$ & s/piece \\
\hline$P T_{k}$ & Picking time in workstation $k$ & s/piece \\
\hline$W L_{k}$ & Workload of workstation $k$ & s/piece \\
\hline$T_{\text {ass }}$ & Total assembly time of one finished product & $\mathrm{min} /$ piece \\
\hline$e_{j}$ & Assembly energy expenditure of task $j$ & $\mathrm{kcal} / \mathrm{piece}$ \\
\hline$e_{p, j w}$ & Picking energy expenditure for task $j$ from SL $w$ & $\mathrm{kcal} / \mathrm{piece}$ \\
\hline$e_{t}$ & Average travel energy expenditure between two workstations & $\mathrm{kcal} / \mathrm{piece}$ \\
\hline$E_{\text {pos }}$ & Energy expenditure for the standing posture & $\mathrm{kcal} / \mathrm{s}$ \\
\hline$A E_{k}$ & Assembly energy expenditure in workstation $k$ & $\mathrm{kcal} / \mathrm{piece}$ \\
\hline$P E_{k}$ & Picking energy expenditure in workstation $k$ & $\mathrm{kcal} / \mathrm{piece}$ \\
\hline$E_{k}$ & Energy expenditure of workstation $k$ & $\mathrm{kcal} / \mathrm{piece}$ \\
\hline
\end{tabular}


on the maximum system throughput; i.e., the $Q_{\text {target }}$ of the system is calculated as the maximum market demand in the considered period.

Knowing the total assembly time ( $T_{\text {ass }}$ ) of the system, needed to assemble one finished product, it is possible to define $K$ as:

$K=\left\lceil T_{\text {ass }} \cdot Q_{\text {target }}\right\rceil$

Moreover, starting from this maximum number of stations, it is possible to define $P V$, which represents the production volume flexibility parameter. It takes into account how much the system is used with respect to its maximum threshold $Q_{\text {target }}$, which is also related to the maximum number of stations $K$ :

$P V=\frac{N_{o p}}{K}[\%]$

Here, $P V=100 \%$ when both systems are working at their maximum rate $\left(N_{o p}=K\right.$ for $\mathrm{WW}$ and $N_{o p}=K^{F W}=K$ for $\left.\mathrm{FW}\right)$. On the other side, when the system throughput is lower than $Q_{\text {target }}$, the number of operators decreases (and, for FW, also the number of workstations decreases), and $P V<100 \%$.

\subsubsection{Assembly line balancing}

Two binary variables are defined as:

$x_{j k}= \begin{cases}1 & \text { if task } \mathrm{j} \text { is assigned to workstation } k \\ 0 & \text { if task } \mathrm{j} \text { is not assigned to workstation } k\end{cases}$

$z_{j k w}=\left\{\begin{array}{l}1 \quad \text { if task } \mathrm{j} \text { is assigned to workstation } k \text { in } S L w \\ 0 \quad \text { if task } \mathrm{j} \text { is not assigned workstation } k \text { in } S L w\end{array}\right.$

The assembly line balancing problem is solved by an objective function that aims to minimize the maximum workload of each workstation $W L_{k}$. It is defined as:

$\theta=\min \left(\max _{k} W L_{k}\right)[s /$ piece $]$

where $W L_{k}$ is the workload of workstation $k$ that includes the assembly and the picking activities. It is defined as:

$W L_{k}=A T_{k}+P T_{k}=\sum_{j=1}^{n}\left(x_{j k} \cdot t_{j}\right)+\sum_{j=1}^{n} \sum_{w=0}^{W}\left(z_{j k w} \cdot t_{p, w}\right)[\mathrm{s} /$ piece $]$

where $A T_{k}$ indicates the total assembly time in the workstation $k$, while $P T_{k}$ indicates the total picking time in workstation $k$. In particular, $t_{j}$ is the assembly time of task $j ; t_{p, w}$ is the picking time from the SL $w$.

In order to consider the energy expenditure of both configurations, the energy expenditure of workstation $k$ $E_{k}$ is defined as:

$$
\begin{aligned}
E_{k}= & E_{p o s} \cdot W L_{k}+\sum_{j=1}^{n}\left(A E_{j k}+P E_{j k}\right) \\
= & E_{p o s} \cdot W L_{k}+\sum_{j=1}^{n}\left(x_{j k} \cdot e_{j}\right) \\
& +\sum_{j=1}^{n} \sum_{w=0}^{W}\left(z_{j k w} \cdot e_{p, j w}\right)[\mathrm{kcal} / \mathrm{piece}]
\end{aligned}
$$

where $A E_{j k}$ is the total energy expenditure of the assembly activity of task $j$ in the workstation $k$, while $P E_{j}$ indicates the total energy expenditure of the picking activity of task $j$ related to workstation $k$. In particular, $E_{p o s}$ is the standard energy expenditure for the maintenance of the standing posture and it is calculated using Garg et al.'s formula [67], as:

$$
E_{p o s}=\frac{0.024 \cdot B W}{60} \quad[\mathrm{kcal} / \mathrm{s}]
$$

where $B W$ is the worker's body weight. The notations $e_{j}$ and $e_{p, j w}$ indicate the energy expenditure for the assembly activity of task $j$ and the energy expenditure for the picking activity of task $j$ from SL $w$, respectively. They are also calculated deriving an energy expenditure per piece from the Garg et al.'s formulas [67], depending on the components' weight $L_{j}$, the operators walking speed, and the characteristics of the various picking and assembly activities [47, 63].

The constraints of the model are:

$\sum_{k=1}^{K} x_{j k} \leq 1 \quad \forall j=1 \ldots n$

$\sum_{k=1}^{K} \sum_{w=0}^{W} z_{j k w} \leq 1 \quad \forall j=1 \ldots n$

$\sum_{k \in\left[E_{j}, L_{j}\right]} k \cdot x_{i k} \leq \sum_{k \in\left[E_{l}, L_{l}\right]} k \cdot x_{j k} \quad \forall(i, j) \in A$

$\sum_{j=1}^{n} z_{j k w} \leq C_{w k} \quad \forall w=0 \ldots W, \forall k=1 \ldots K$

$z_{j k w} \leq x_{j k} \quad \forall j=1 \ldots n, \forall k=1 \ldots K, \forall w=1 \ldots W$

$\sum_{w=0}^{W} \sum_{j=1}^{n}\left[\left(z_{j k w} \cdot t_{p, w}\right)+\left(x_{j k} \cdot t_{j}\right)\right] \leq \max W L k$

$\frac{E_{k}}{W L_{k}} \cdot 60 \leq 4.29 \forall k=1 \ldots K$

$W L_{k}>0 \quad \forall k=1 \ldots K$

$x_{j k} \in\{0,1\} \quad \forall j=1 \ldots n, \forall k=1 \ldots K$

$z_{j k w} \in\{0,1\} \quad \forall j=1 \ldots n, \forall k=1 \ldots K, \forall w=1 \ldots W$

Constraints (9) and (10) assure that each task $j$ is assigned only to one workstation $k$ and that each component of task $j$ is assigned just to one SL $w$. Constraints (11) are for precedence relations, with $A$ set of arcs in the precedence diagram. Equation (12) is for the capacity constraint of each workstation $k$ : the number of components stored in each SL $w$ has to be equal or lower of $C_{w k}$, which is the maximum capacity of SL $w$ in workstation $k$. Constraint (13) assures a proper assignment of the tasks to the available storage locations, while Eq. (14) limits the cycle time of the assembly line; i.e., the 
total assembly and picking time for every task $j$ must be minor of the final cycle time. Equations (15) and (16) refer to the energy expenditure of each station, which has to be lower than the limit suggested by [68] to avoid the need for rest allowances. Constraints (17) and (18) set the domains of the decision variables.

\subsubsection{Evaluation and comparison of the systems configurations}

In order to evaluate $\mathrm{FW}$ and WW systems, some parameters are defined. First, it is considered the productivity of the system as:

$Q=\frac{3600}{\max \left(W L_{k}\right)} \quad[$ pieces $/ h]$

Then, the total workload for the two configurations $T_{\text {tot, FW }}$ and $T_{t o t, W W}$ are calculated with:

$T_{\text {tot }, F W}=\sum_{k=1}^{K} W L_{k} \quad[s /$ piece $]$

$T_{\text {tot }, W W}=\sum_{k=1}^{K} W L_{k}+K \cdot \frac{D}{v} \quad[s /$ piece $]$

and compared with:

$\Delta T=\frac{T_{t o t, W W}-T_{t o t, F W}}{T_{t o t, W W}} \quad[\%]$

Then, if $\Delta T>0$, the FW configuration is preferable from a workload point of view; otherwise, if $\Delta T<0$, the WW configuration is the best one. A similar formulation is defined also for the total energy expenditures per finished product:

$E_{\text {tot }, F W}=\sum_{k=1}^{K} E_{k} \quad[\mathrm{kcal} / \mathrm{piece}]$

$E_{\text {tot }, W W}=\sum_{k=1}^{K} E_{k}+K \cdot e_{t} \quad[\mathrm{kcal} / \mathrm{piece}]$

$\Delta E=\frac{E_{t o t, W W}-E_{t o t, F W}}{E_{t o t, W W}}[\%]$

If $\Delta E>0$, the FW configuration is preferable from an energy expenditure point of view; otherwise, if $\Delta E<0$, the WW configuration is the best one.

\section{Parametric analysis}

The parametric analysis of this section aims at showing the behavior and the comparison of the two systems to derive also some general insights. Table 4 reports the input values of the considered parameters; the values are assumed based on existing contributions and on the authors' experience. The picking times from the storage locations $t_{p, w}$ are calculated by applying the MOST method [12]. The values of the energy expenditures have been calculated based on Garg et al.'s formulas [67] according to the movements performed by the operators, to their durations, and to the components' weights $[47,63]$. The values of the parameter $P V$ are calculated from the ratio of all the possible combinations of $N_{o p}$ and $K$ (Eq. (2)). For $C_{w k}$, it has been fixed the value of $C_{0 k}$ as reported in Table 4 , while for the other storage locations, it has been calculated as $C_{1 k}=C_{0 k}, C_{2 k}=C_{0 k} / 2$, and $C_{3 k}=n-K \cdot\left(C_{0 k}+\right.$ $C_{1 k}+C_{2 k}$ ).

The various combinations of all the varying parameters lead to 265,000 different scenarios. For each scenario, the factors defined in Eq. (2) and (19-25) are calculated. All the results have been further analyzed with Minitab v.19 and summarized in the following graphs.

Figure 3 shows the Pareto chart of the standardized effects of $\Delta T$ and $\Delta E$. These allow to understand the importance of various parameters on $\Delta T$ and $\Delta E$, and, then, the importance that they have on the choice between a FW system with respect to a WW one. Here, it can be seen that the most important effects are $P V$ and the combination of $P V$ and $T_{\text {ass }}$ for both cases. Then, with a decreasing importance, $\Delta T$ is more influenced by the number of tasks and parts $n$, by its combination with $P V, T_{a s s}$, and $C_{0 k}$, by $T_{a s s}$ and $K$. On the other side, $\Delta E$ is affected by $T_{\text {ass }}$ itself and, then, by $n$, the combination of $n$ and $P V$ and the combination of $n$ and $C_{0 k}$.

Based on the parameters that are identified as the most relevant ones, Fig. 4 reports the main effects plots, to show how $\Delta T$ and $\Delta E$ change according to the values of these parameters. First of all, it is interesting to see how most of the values of $\Delta T$ and $\Delta E$ are lower than 0 , with a convenience of the WW system with respect to the FW one. Moreover, although the values $\Delta T$ and $\Delta E$ are different, their reported trends are similar. For this reason, the $\Delta T$ and $\Delta E$ as a function of the investigated parameters will be discussed together. In particular, with $T_{\text {ass }}$, we see that the WW configuration is always the best one ( $\Delta T$ and $\Delta E$ always $<0$ ), but with a convenience that decreases with the increase of the total assembly time. Moreover, the effect of $T_{\text {ass }}$ on $\Delta E$ is higher than on $\Delta T$, due to the consideration of different energy expenditures according to the storage locations and to the weights of the items. The plots for $K$ show that this parameter does not influence much the difference between FW and WW. Here, the FW system is slightly better than the WW one for the low value of $K(K=2)$ and for the highest one $(K=10)$. In fact, both for $K=2$ and $K=10$, there is a great incidence of the walking activity (in the WW system) on the assembly process. This interesting effect highlights how, in case of a low number of workstations $K$, the FW system is advantaged, since the material exposure will be quite the same for FW and WW. Again, in case of a high number of workstations $K$, the FW system is still the best one, due to the impact of the travel activity of the operators in the WW system. Then, the WW system turns out to be preferable for intermediate values of the number of workstations $K$. In fact, looking at Fig. 4 , the best 
Table 4 Parameters and values for the parametric analysis

\begin{tabular}{|c|c|c|}
\hline Parameter & Value(s) & Unit \\
\hline$n$ & $20,40,60,80,100$ & - \\
\hline$K$ & $2,3,4,5,6,7,8,9,10$ & - \\
\hline$w$ & $0,1,2,3$ & - \\
\hline$N_{o p}$ & $1,2,3,4,5,6,7,8,9,10$ & - \\
\hline$P V$ & $\begin{array}{l}11.1,12.5,14.2,16.6,20,22.2,25,28.5,30,33.3,37.5,40,42.8,44.4,50,55.5,57.1,60 \\
\quad 62.5,66.6,70,71.4,75,77.7,80,83.3,85.7,87.5,88.8,90,100\end{array}$ & $\%$ \\
\hline$T_{\text {ass }}$ & $\begin{array}{l}180,360,540,720,900,1080,1260,1440,1620,1800,1980,2160,2340,2520,2700,2880, \\
\quad 3060,3240,3420,3600\end{array}$ & $\min /$ piece \\
\hline $\bar{L}$ & $0.1,0.5,1,2,4$ & $\mathrm{~kg}$ \\
\hline$D$ & $2,3,4,5$ & $\mathrm{~m}$ \\
\hline$v$ & 1 & $\mathrm{~m} / \mathrm{s}$ \\
\hline$B W$ & 80 & $\mathrm{~kg}$ \\
\hline$C_{0 k}$ & $2,4,6,8,10^{*}$ & parts \\
\hline$t_{p, 0}$ & 1.44 & $\mathrm{~s}$ \\
\hline$t_{p, 1}$ & 2.52 & $\mathrm{~s}$ \\
\hline$t_{p, 2}$ & 3.60 & $\mathrm{~s}$ \\
\hline$t_{p, 3}$ & 5.04 & $\mathrm{~s}$ \\
\hline
\end{tabular}

* The values of $C_{w k}$ for SL1, SL2, and SL3 have been calculated according to $C_{0 k}$ and $n$

WW performances are for $K$ from 4 to 7 . Looking at the plots related to the number of parts $n$, it can be seen that higher values of $n$ lead to the convenience of the WW system. Of course, if there are many parts to store in the assembly line, it is preferable to have them on closer and more ergonomic storage locations, which is always the case for the WW system. In the FW system, since the number of workstations decreases with the throughput of the line, there are some scenarios in which the parts have to be stored in farther and less ergonomic locations. The plots for the traveling distance $D$ highlight that this parameter does not have a great influence on the results. Of course, the higher the distance, the lower the convenience of a WW configuration. However, it is interesting to see that, based on this parameter, the WW configuration turns out to be always the best one anyway ( $\Delta T$ and $\Delta E<0$ ). On the other side, the trends for $C_{0 k}$ demonstrate that the two systems are quite similar from this point of view, only with a more marked preference for $\mathrm{FW}$ when $C_{0 k}=2$. In fact, if $C_{0 k}$ is low, it means that there are few spaces for the storage of the components in front of the operator, and the two configurations are similar from this point of view, with the FW being better since the operator does not have to travel. For the intermediate values of $C_{0 k}$, the WW system is better because the travel activity impacts less with respect to the picking activity. On the other side, if $C_{0 k}$ is high, it means that there is more space for the storage of the components in front of the operator, and, then, the convenience of using WW respect to FW becomes lower. The trend of $C_{0 k}$ highlights the incidence of
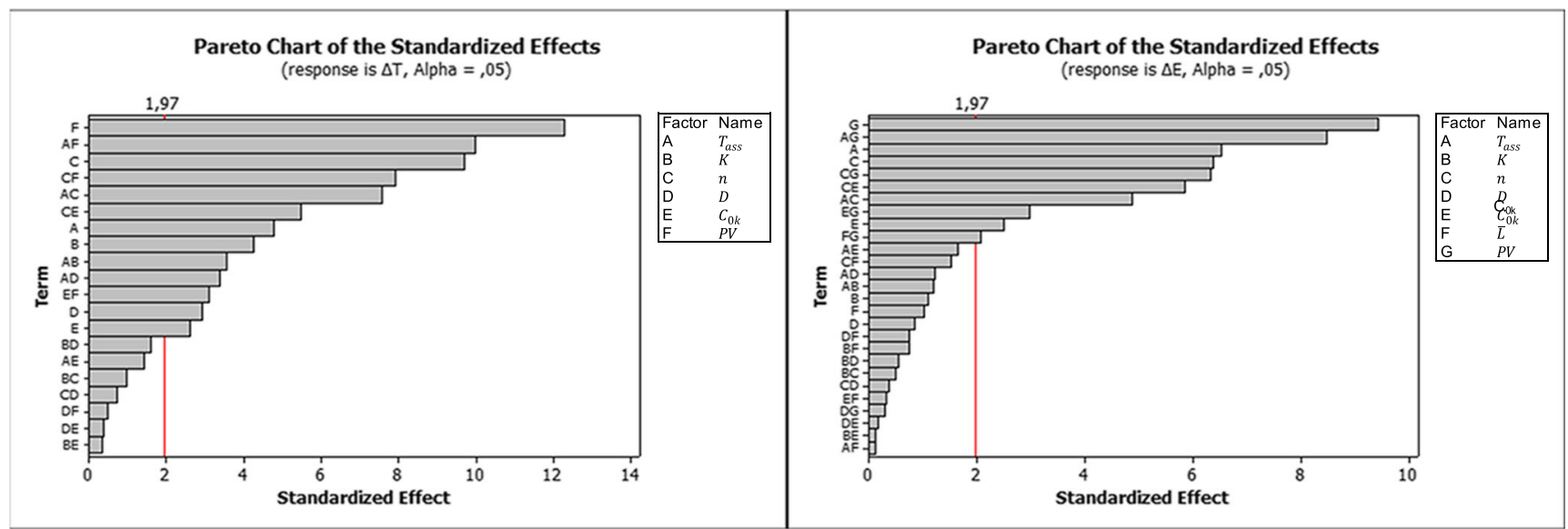

Fig. 3 Pareto chart of the standardized effects of $\Delta T$ (left) and $\Delta E$ (right) 

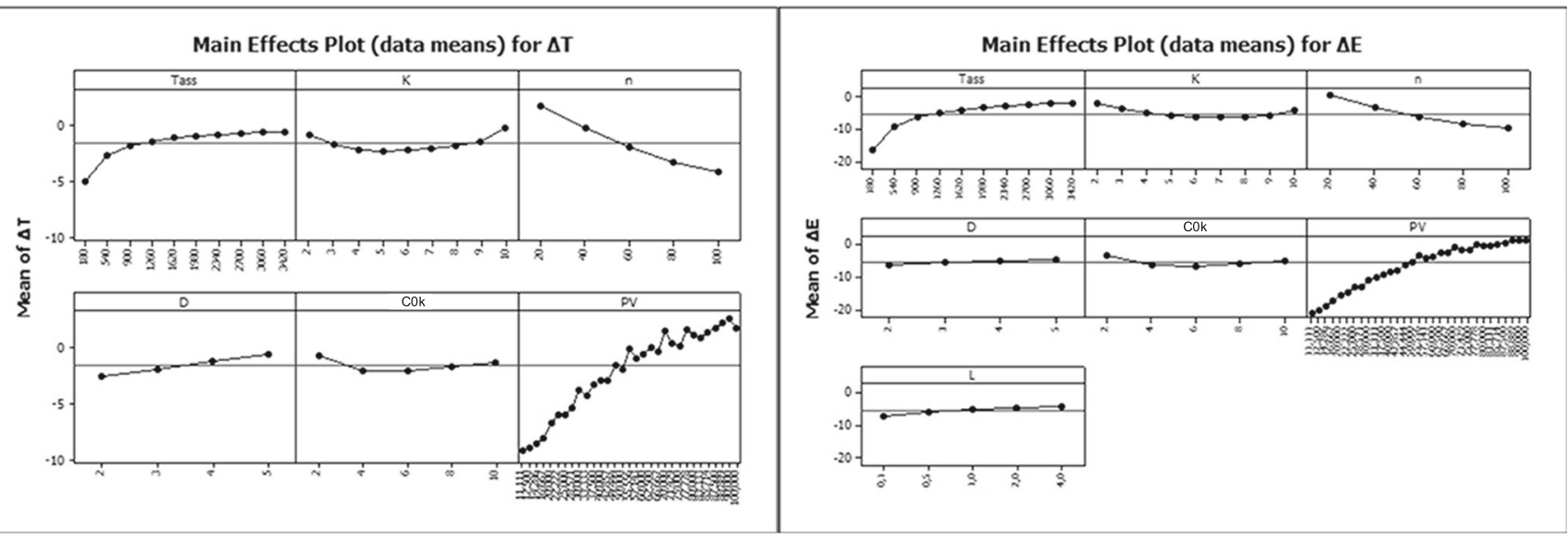

Fig. 4 Main effects' plots for $\Delta T$ (left) and $\Delta E$ (right)

material exposure and/or of the travel activity on the convenience of the two system configurations. The plots of the production volume $P V$ confirm its high influence on the choice between FW and WW systems. Of course, for high values of $P V$, the FW system turns out to be the best one, since, compared to the WW one, it does not require the traveling activity of the operators. On the other side, for low values of $P V$, the WW system is better than the FW one, because, by keeping the same number of workstations, it always warrants the storage of the parts on the best storage locations. Finally, on the right of Fig. 4 , the plot of $\bar{L}$ is reported, in which it can be seen that this parameter does not have a very significant effect on $\Delta E$. This is probably due to the fact that the difference in terms of energy expenditure between FW and WW is also related to the assembly activity and to the traveling one, which does not depend on the weights of the components in their studied range, as defined in the assumption section.

Following the findings of the Pareto charts, some graphs useful to derive further insights concerning the comparison between FW and WW systems are proposed. These are contour plots, showing various convenience areas of FW and WW based on $\Delta T$ and $\Delta E$, varying $P V, T_{a s s}$, and $n$, which are the three parameters with a higher influence on $\Delta T$ and $\Delta E$ (Fig. 3). The red areas indicate the convenience of the WW configuration, while the green ones refer to the convenience of the $\mathrm{FW}$ one.

Figure 5 reports the contour plots of $\Delta T$ and $\Delta E$ with $P V$ and $T_{\text {ass. }}$. From a workload point of view, the WW system is always preferable when $P V<60 \%$, for all values of $T_{\text {ass }}$, while from an energy expenditure point of view, its convenience area is larger, starting from $P V<85 \%$.

The contour plots of Fig. 6 show the influence of $P V$ and of the number of tasks $n$. In the plot on the left of Fig. 6 (referring to $\Delta T$ ), for low values of $P V(P V<20 \%)$, a WW system is always preferable; on the other side, for $P V>20 \%$, it also depends on the values of $n$. The WW system turns out to be better when $n$ is high and $P V<$ $80 \%$; for $P V>80 \%$, the FW system outperforms the WW one. In the plot on the right of Fig. 6 (referring to $\Delta E$ ), the trend is similar, but with the thresholds of $P V=30 \%$ and $P V=90 \%$.
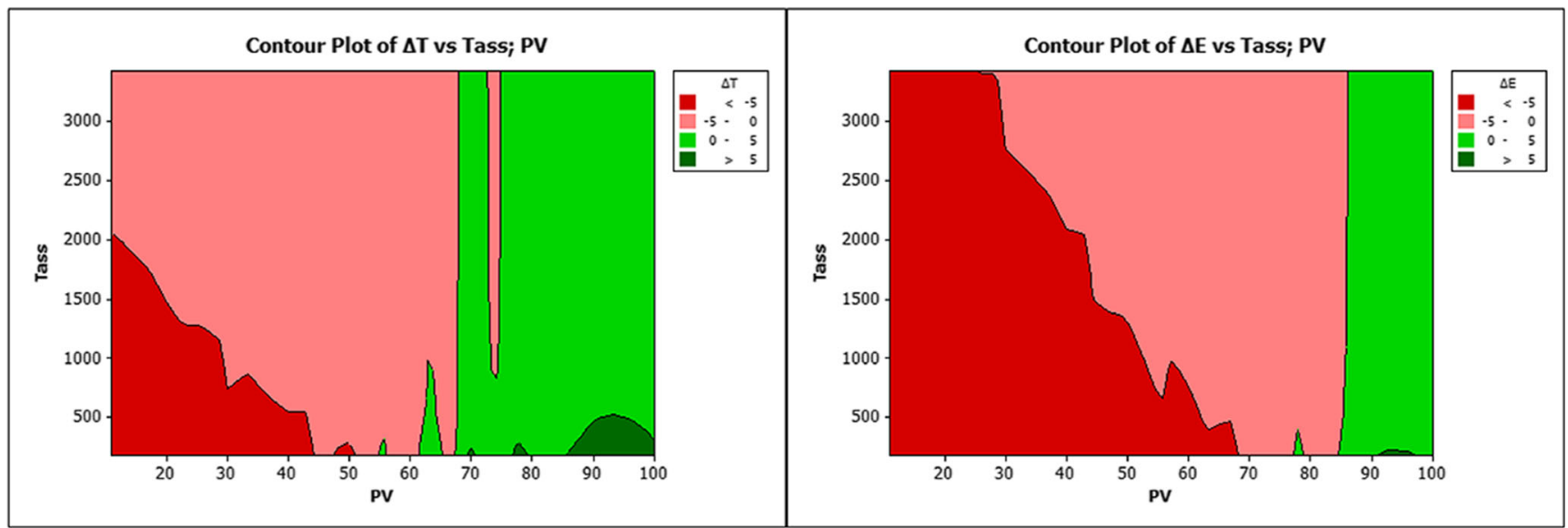

Fig. 5 Contour plots of $\Delta T$ and $\Delta E$ with $T_{\text {ass }}$ and $P V$ 

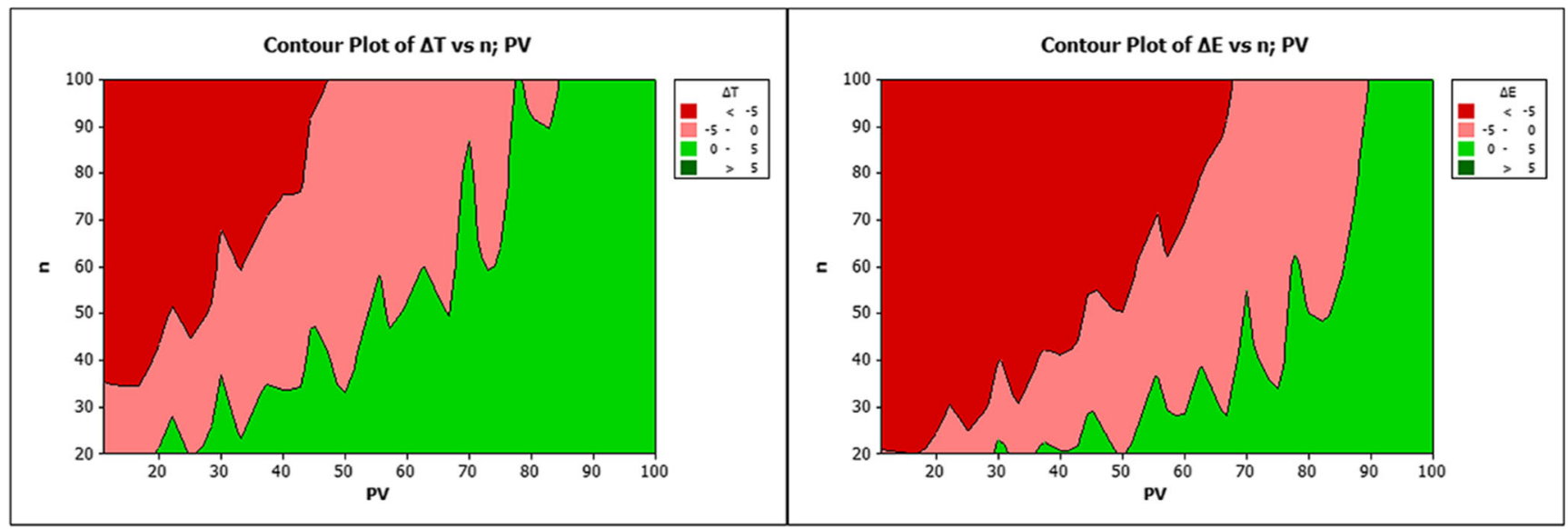

Fig. 6 Contour plots of $\Delta T$ and $\Delta E$ with $n$ and $P V$

The four contour plots confirm the high influence of material exposure on the workloads and on the energy expenditures and, then, on the convenience of the WW system.

A final analysis is focused on the study of the scenarios from the energy expenditure perspective, considering the energy expenditure limit as defined by [68]. On a total of 265,000 scenarios, the FW strategy exceeds the limit of 4.29 $\mathrm{kcal} /$ min per operator in 78,760 scenarios $(29.72 \%)$, while the WW one in 74,864 of these $(28.25 \%)$. Then, there are 3896 scenarios in which only the WW is able to respect the energy expenditure limit. Figure 7 shows how the 74,864 scenarios in which the limit is exceeded by both systems are distributed according to the parameters $\bar{L}, C_{0 k}, n$, and $T_{a s s}$. As it could be expected, it can be seen that most of the scenarios refer to high values of components average weight $\bar{L}$, while the other parameters have a slighter influence. Moreover, focusing on the 3896 scenarios in which only the FW exceeds the energy limit, it can be observed that these mostly refer to cases with the higher number of components $n$ and lower values of $T_{\text {ass }}$. The first result is related to the fact that a higher $n$ leads to a higher chance of having the components stored in the worst storage locations for the FW strategy. The second one,
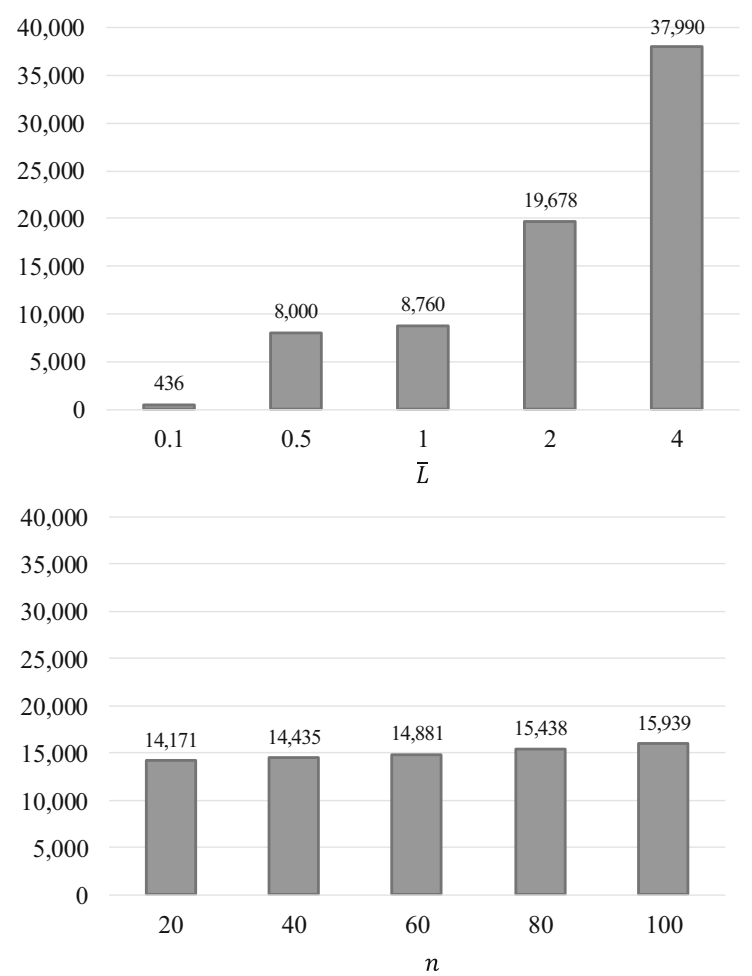

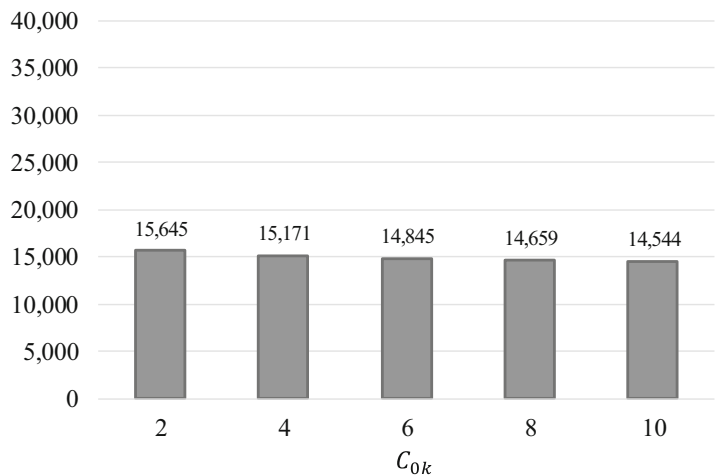

40,000

35,000

30,000

25,000

20,000

15,000

$\begin{array}{lllllllllll}10,000 & 8,364 & 7,873 & 7,561 & 7,410 & 7,340 & 7,318 & 7,287 & 7,264 & 7,232 & 7,215\end{array}$

5,000

$180 \quad 540 \quad 900 \quad 1260162019802340 \quad 270030603420$

$T_{\text {ass }}$

Fig. 7 Distribution of the 74,864 scenarios in which FW and WW systems exceed the energy limit 
Fig. 8 Precedence diagram

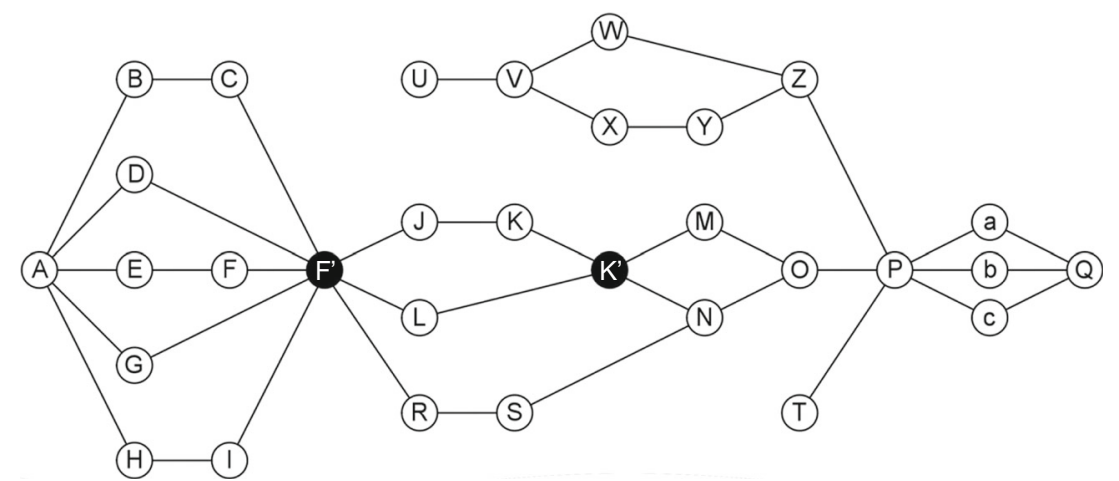

instead, is due to the fact that with a lower $T_{a s s}$, the picking time and energy expenditure have a greater impact on the total time, which is considered in the calculation of the energy expenditure per minute (Eq. (15)).

\section{Case study}

The practical example reported in this section deals with a multinational company located in the north of Italy that produces and sells water pumps for industrial, agricultural, and domestic applications. The focus here is on one of its assembly lines, which has a U-shape layout and it is composed of a maximum of 5 workstations (as in Fig. 1). Each workstation has 5 different storage locations, displayed as the ones of Fig. 2 (SL0, SL1, SL2, SL3, SL4). Figure 8 reports the precedence diagram of the finished product, which needs 31 tasks to be assembled (29 real tasks and 2 dummy ones). Table 5 summarizes some characteristics of the analyzed case, which have been used as input values of the comparison model. Table 6 shows the input data referred to the 31 assembly tasks: weight of the part, assembly time and energy expenditure, picking times, and energy expenditures for each storage location.

The model for balancing the system and for assigning the parts to the storage locations has been solved with

Table 5 Characteristics of the assembly system of the case study

\begin{tabular}{lll}
\hline Parameter & Value(s) & Unit \\
\hline$n$ & 31 & - \\
$K$ & 5 & - \\
$w$ & $0,1,2,3,4$ & - \\
$N_{o p}$ & $1,2,3,4,5$ & - \\
$P V$ & $20,40,60,80,100$ & $\%$ \\
$D$ & 3 & $\mathrm{~m}$ \\
$v$ & 1 & $\mathrm{~m} / \mathrm{s}$ \\
$B W$ & 80 & $\mathrm{~kg}$ \\
$C_{w k}$ & $2,2,3,4, n-\sum_{w=0}^{3} C_{w k} / K^{F W}$ & parts \\
\hline
\end{tabular}

IBM Cplex v12.8. The obtained objective functions $\theta$, referring to the 5 different levels of $P V$, are reported in Table 7. The comparison of the two possible configurations FW and WW has been done through the calculation of $T_{t o t, F W}, T_{t o t, W W}, \Delta T, E_{t o t, F W}, E_{t o t}, W W$, and $\Delta E$, reported in Table 7 . Negative values of $\Delta T$ and $\Delta E$ indicate the convenience of the WW configuration. Figure 9 highlights how the FW configuration turns out to be the best one when $P V=100 \%$. On the other side, decreasing $P V$, the WW configuration is preferable $(P V<70 \%$ for time and $P V<85 \%$ for energy), since it warrants better time and energy performances. In particular, since the number of workstations is always the same for the WW configuration, it allows to store all the needed material always in closer and more ergonomic storage locations. This advantage is able to cover the time and the energy expenditure needed for the travel activity between workstations.

\section{Implications of the presented model}

As shown in the previous sections, the introduced model allows to do an interesting comparison between FW and WW systems from two different perspectives, i.e., time and energy expenditure. The model itself shows its ease of application, which guarantees its usefulness both for researchers and practitioners. In fact, the model can be applied to understand which configuration between FW and WW is the best one for a certain production setting, as shown in Section 5.

The results obtained through the parametric analysis and from the case study help the closing of the research gap introduced in Section 2, but they can have an impact also for practitioners. In fact, they demonstrate that, in general, WW turns out to be preferable when the assembly system is not working at its maximum pace and that this configuration is not worse from an energy expenditure point of view. Then, these findings can promote new and wider practical applications of WW systems instead of FW ones. 
Table 6 Characteristics of the assembly tasks of the case study

\begin{tabular}{|c|c|c|c|c|c|c|c|c|c|c|c|c|c|}
\hline Task & $L_{j}$ & $t_{j}$ & $t_{p, 0}$ & $t_{p, 1}$ & $t_{p, 2}$ & $t_{p, 3}$ & $t_{p, 4}$ & $e_{j}$ & $e_{p, 0}$ & $e_{p, 1}$ & $e_{p, 2}$ & $e_{p, 3}$ & $e_{p, 4}$ \\
\hline A & 0.38 & 24 & 1.44 & 2.52 & 3.60 & 5.04 & 7.20 & 1.30 & 0.13 & 0.24 & 0.55 & 0.55 & 0.66 \\
\hline B & 0.62 & 46 & 1.44 & 2.52 & 3.60 & 5.04 & 7.20 & 3.22 & 0.16 & 0.29 & 0.62 & 0.56 & 0.66 \\
\hline $\mathrm{C}$ & 0.15 & 13 & 1.44 & 2.52 & 3.60 & 5.04 & 7.20 & 0.50 & 0.10 & 0.19 & 0.49 & 0.55 & 0.65 \\
\hline D & 0.10 & 7 & 1.44 & 2.52 & 3.60 & 5.04 & 7.20 & 0.26 & 0.10 & 0.18 & 0.48 & 0.54 & 0.65 \\
\hline $\mathrm{E}$ & 0.52 & 25 & 1.44 & 2.52 & 3.60 & 5.04 & 7.20 & 1.59 & 0.14 & 0.26 & 0.59 & 0.56 & 0.66 \\
\hline $\mathrm{F}$ & 0.43 & 15 & 1.44 & 2.52 & 3.60 & 5.04 & 7.20 & 0.88 & 0.14 & 0.25 & 0.57 & 0.55 & 0.66 \\
\hline $\mathrm{F}^{\prime}$ & 0 & 0 & 0 & 0 & 0 & 0 & 0 & 0 & 0 & 0 & 0 & 0 & 0 \\
\hline G & 0.20 & 5 & 1.44 & 2.52 & 3.60 & 5.04 & 7.20 & 0.23 & 0.11 & 0.20 & 0.50 & 0.55 & 0.65 \\
\hline $\mathrm{H}$ & 0.46 & 38 & 1.44 & 2.52 & 3.60 & 5.04 & 7.20 & 2.24 & 0.14 & 0.26 & 0.58 & 0.55 & 0.66 \\
\hline I & 0.70 & 11 & 1.44 & 2.52 & 3.60 & 5.04 & 7.20 & 0.86 & 0.17 & 0.30 & 0.64 & 0.56 & 0.66 \\
\hline $\mathrm{J}$ & 0.65 & 80 & 1.44 & 2.52 & 3.60 & 5.04 & 7.20 & 5.75 & 0.16 & 0.29 & 0.62 & 0.56 & 0.66 \\
\hline K & 0.49 & 85 & 1.44 & 2.52 & 3.60 & 5.04 & 7.20 & 5.14 & 0.14 & 0.26 & 0.58 & 0.56 & 0.66 \\
\hline $\mathrm{K}^{\prime}$ & 0 & 0 & 0 & 0 & 0 & 0 & 0 & 0 & 0 & 0 & 0 & 0 & 0 \\
\hline $\mathrm{L}$ & 0.75 & 25 & 1.44 & 2.52 & 3.60 & 5.04 & 7.20 & 2.00 & 0.17 & 0.31 & 0.66 & 0.56 & 0.66 \\
\hline $\mathrm{M}$ & 0.34 & 60 & 1.44 & 2.52 & 3.60 & 5.04 & 7.20 & 3.01 & 0.13 & 0.23 & 0.54 & 0.55 & 0.66 \\
\hline $\mathrm{N}$ & 0.50 & 65 & 1.44 & 2.52 & 3.60 & 5.04 & 7.20 & 3.99 & 0.14 & 0.26 & 0.58 & 0.56 & 0.66 \\
\hline $\mathrm{O}$ & 0.22 & 45 & 1.44 & 2.52 & 3.60 & 5.04 & 7.20 & 1.89 & 0.11 & 0.21 & 0.51 & 0.55 & 0.65 \\
\hline $\mathrm{P}$ & 0.64 & 95 & 1.44 & 2.52 & 3.60 & 5.04 & 7.20 & 6.75 & 0.16 & 0.29 & 0.62 & 0.56 & 0.66 \\
\hline Q & 0.47 & 16 & 1.44 & 2.52 & 3.60 & 5.04 & 7.20 & 0.98 & 0.14 & 0.26 & 0.58 & 0.55 & 0.66 \\
\hline $\mathrm{R}$ & 0.32 & 40 & 1.44 & 2.52 & 3.60 & 5.04 & 7.20 & 1.96 & 0.12 & 0.22 & 0.54 & 0.55 & 0.66 \\
\hline S & 0.25 & 25 & 1.44 & 2.52 & 3.60 & 5.04 & 7.20 & 1.12 & 0.12 & 0.21 & 0.52 & 0.55 & 0.66 \\
\hline $\mathrm{T}$ & 0.16 & 15 & 1.44 & 2.52 & 3.60 & 5.04 & 7.20 & 0.59 & 0.10 & 0.19 & 0.50 & 0.55 & 0.65 \\
\hline $\mathrm{U}$ & 0.12 & 12 & 1.44 & 2.52 & 3.60 & 5.04 & 7.20 & 0.45 & 0.10 & 0.18 & 0.48 & 0.55 & 0.65 \\
\hline V & 0.18 & 18 & 1.44 & 2.52 & 3.60 & 5.04 & 7.20 & 0.73 & 0.11 & 0.20 & 0.50 & 0.55 & 0.65 \\
\hline W & 0.35 & 52 & 1.44 & 2.52 & 3.60 & 5.04 & 7.20 & 2.65 & 0.13 & 0.23 & 0.54 & 0.55 & 0.66 \\
\hline$X$ & 0.59 & 37 & 1.44 & 2.52 & 3.60 & 5.04 & 7.20 & 2.52 & 0.15 & 0.28 & 0.61 & 0.56 & 0.66 \\
\hline $\mathrm{Y}$ & 0.41 & 21 & 1.44 & 2.52 & 3.60 & 5.04 & 7.20 & 1.18 & 0.14 & 0.24 & 0.56 & 0.55 & 0.66 \\
\hline Z & 0.31 & 65 & 1.44 & 2.52 & 3.60 & 5.04 & 7.20 & 3.12 & 0.12 & 0.22 & 0.54 & 0.55 & 0.66 \\
\hline $\mathrm{a}$ & 0.49 & 8 & 1.44 & 2.52 & 3.60 & 5.04 & 7.20 & 0.52 & 0.14 & 0.26 & 0.58 & 0.56 & 0.66 \\
\hline $\mathrm{b}$ & 0.26 & 13 & 1.44 & 2.52 & 3.60 & 5.04 & 7.20 & 0.61 & 0.12 & 0.22 & 0.52 & 0.55 & 0.66 \\
\hline $\mathrm{c}$ & 0.18 & 21 & 1.44 & 2.52 & 3.60 & 5.04 & 7.20 & 0.84 & 0.11 & 0.20 & 0.50 & 0.55 & 0.65 \\
\hline
\end{tabular}

\section{Conclusions}

The present paper has reported a mathematical model to compare the FW assembly strategy and the WW one, by taking into account the impact of their differences both in terms of performed activities during assembly and of material exposure at the assembly workstations. The detailed parametric analysis and the proposed case study highlight that the FW is the best one when the system is working at its maximum throughput, while the WW strategy turns out to be preferable for the lower values of market

Table 7 Results of the case study

\begin{tabular}{|c|c|c|c|c|c|c|c|c|c|c|c|}
\hline K & $K^{F W}$ & $N_{o p}$ & $P V(\%)$ & $\theta$ & $Q$ & $T_{t o t, F W}$ & $T_{t o t, W W}$ & $\Delta T(\%)$ & $E_{t o t, F W}$ & $E_{t o t, W W}$ & $\Delta E(\%)$ \\
\hline 5 & 5 & 5 & 100 & 213.12 & 16.89 & 1059.04 & 1074.04 & 1.40 & 65.95 & 67.07 & 1.66 \\
\hline 5 & 4 & 4 & 80 & 272.84 & 13.20 & 1065.88 & 1074.04 & 0.76 & 67.50 & 67.07 & -0.65 \\
\hline 5 & 3 & 3 & 60 & 366.80 & 9.82 & 1082.44 & 1074.04 & -0.78 & 68.90 & 67.07 & -2.74 \\
\hline 5 & 2 & 2 & 40 & 557.24 & 6.46 & 1112.32 & 1074.04 & -3.56 & 70.78 & 67.07 & -5.53 \\
\hline 5 & 1 & 1 & 20 & 1152.64 & 3.12 & 1152.64 & 1074.04 & -7.32 & 73.46 & 67.07 & -9.54 \\
\hline
\end{tabular}



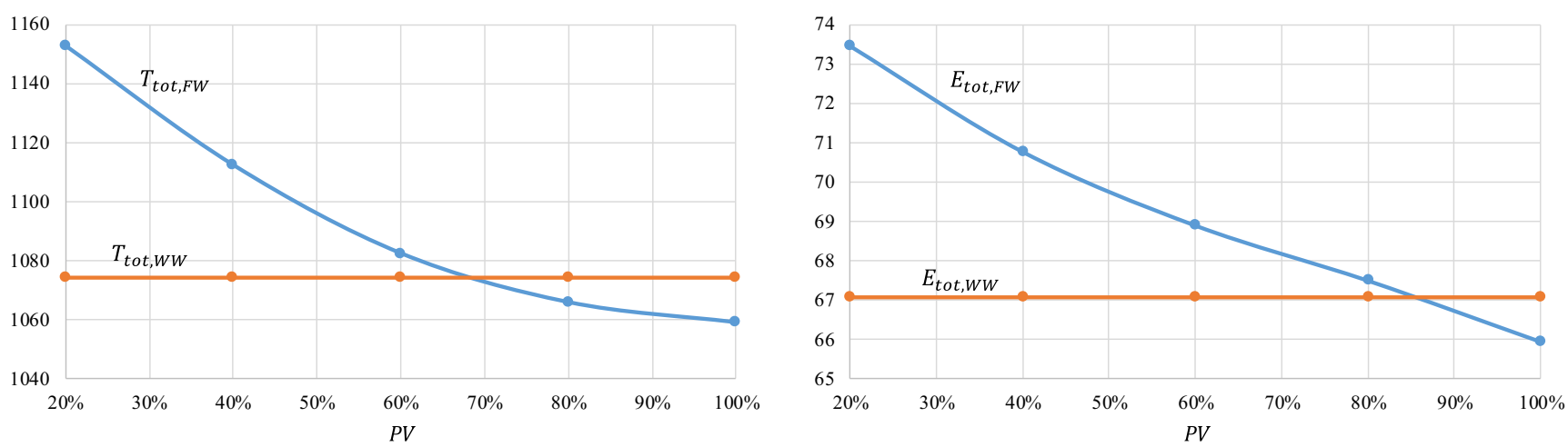

Fig. 9 Comparison of FW and WW configurations from time and energy perspectives

demand, both from a time and an energy expenditure perspective. As far as the time performances are concerned, the WW system performs better than the FW one when the production volume flexibility parameter $P V$ is lower than $100 \%$, since in the FW configuration, there are fewer workstations and, then, a higher employ of the farthest storage locations for the components. A similar result can be seen also with energy expenditures. Moreover, the WW system becomes better than the FW one before from the energy expenditure point of view and later also from the time performance point of view. This is shown by the contour plots of Figs. 5 and 6, where the red areas are larger when considering the percentage difference of the energies $\Delta E$ with respect to the percentage difference of the times $\Delta T$, but also by the plots of Fig. 9, in which the intersection of the two curves of the total energy expenditures per finished product $E_{t o t, F W}$ and $E_{\text {tot, } W W}$ is for higher values of $P V$ with respect to the one of the curves of the total workload $T_{\text {tot, } F W}$ and $T_{\text {tot, } W W}$, with a consequent higher convenience area of the WW system. Therefore, there are some cases in which the WW assembly strategy turns out to be better than the FW one from the energy expenditure point of view even if it is not from the time point of view. In other words, if the WW configuration is the best one from the energy expenditure point of view, it could not be from the time one, while if the WW configuration is the best one from the time point of view, it is also from the energy expenditure one. On the other side, if the FW configuration is the best one from the time point of view, it could not be from the energy expenditure one. Finally, from the parametric analysis, it has been derived that the WW strategy is able to satisfy the operators' energy expenditure limit [68] for a higher number of scenarios than the FW one: the travel activity of the walking operators has a lower impact on the overall performances than the components picking activity of the fixed operators.

Although the proposed model presents some benefits and has led to interesting outcomes, it also has some limitations. These are mainly related to the assumptions introduced in Section 3.1, but, according to the authors, they do not lead to a loss of generalizability of the obtained results. For example, the model is based on deterministic assembly and picking times, with the latter ones which do not change according to the part weight, on the consideration of male operators, all with the same skill level and on the neglecting of the effect of fatigue on tasks' execution performance. For sure, it would be interesting to extend the current model by removing one or more of these assumptions or by considering different applications.

In this direction, future research in this field could further investigate the differences between the two systems by considering also different assembly times, with FW being faster since generally more focused on fewer assembly tasks. This could be modeled through the consideration of the learning curves and of the learning and forgetting principles [69]. Moreover, it would be interesting to integrate also the availability of the operators according to their different energy expenditures [70] as well as to include ergonomics evaluations both in the line balancing and in the comparison model, for example using motion analysis systems [71]. Another perspective of evaluation could be the modeling of the economic impact of the two strategies, considering all the possible emerging costs. Finally, although similar approaches have already been introduced for the study of other systems, such as standard assembly systems or warehouse picking systems [47, 59], the present model can be extended and used to compare also other kinds of assembly systems, such as the fishbone ones [9].

Contributions The corresponding author M. Faccio has been responsible for planning and coordinating the steps of the research. M. Calzavara, I. Zennaro, and M. Faccio have been responsible for writing and reviewing this paper, together with the quantitative model proposal and the analysis. A. Persona has been responsible for revising the paper, including the suitable structure and contents of this paper.

Funding Open Access funding provided by Università degli Studi di Padova.

\section{Compliance with ethical standards}

Conflict of interest The authors declare that they have no conflict of interest. 
Code availability Not applicable.

Ethical approval This paper is new. Neither the entire paper nor any part of its content has been published or has been accepted elsewhere. It is not being submitted to any other journal as well.

\section{Consent to participate Not applicable}

\section{Consent to publish Not applicable}

Open Access This article is licensed under a Creative Commons Attribution 4.0 International License, which permits use, sharing, adaptation, distribution and reproduction in any medium or format, as long as you give appropriate credit to the original author(s) and the source, provide a link to the Creative Commons licence, and indicate if changes were made. The images or other third party material in this article are included in the article's Creative Commons licence, unless indicated otherwise in a credit line to the material. If material is not included in the article's Creative Commons licence and your intended use is not permitted by statutory regulation or exceeds the permitted use, you will need to obtain permission directly from the copyright holder. To view a copy of this licence, visit http://creativecommons.org/licenses/by/4.0/.

\section{References}

1. Atiya A, Lee L, Ke X (2010) An integrated design support methodology for walking worker assembly lines. In: Proceedings of the International MultiConference of Engineers and Computer Scientists 2010. IMECS, pp 1612-1617

2. Ritchie M, Dewar R, Simmons J (1999) The generation and practical use of plans for manual assembly using immersive virtual reality. Prof Eng Publ 213(5):461-466

3. Braun W, Rebollar R, Schiller E (1996) Computer aided planning and design of manual assembly systems. Int J Prod Res 34(8): 2317-2333

4. Heilala J, Voho P (2001) Modular reconfigurable flexible final assembly system. Assem Autom 21(1):20-28

5. Rosati G, Faccio M, Finetto C, Carli A (2013) Modelling and optimization of fully flexible assembly systems (F-FAS). Assem Autom 33(2):165-174

6. Barbazza L, Faccio M, Oscari F, Rosati G (2017) Agility in assembly systems: a comparison model. Assem Autom 37(4):411-421

7. Wang Q, Owen GW, Mileham AR (2005) Comparison between fixed- and walking-worker assembly lines. Proc Inst Mech Eng B J Eng Manuf 219(11):845-848

8. Yoshimura M, Yoshida S, KonishI Y et al (1999) A rapid analysis method for production line design. Int J Prod Res 44(6):1171-1192

9. Azzi A, Battini D, Faccio M, Persona A (2012) Sequencing procedure for balancing the workloads variations in case of mixed model assembly system with multiple secondary feeder lines. Int $\mathbf{J}$ Prod Res 50(21):6081-6098

10. Andrea R (2019) Confronto tra sistemi di assemblaggio manuale fw e ww. Master Thesis, University Of Padova

11. Nakade K, Ohno K (2003) Separate and carousel type allocations of workers in a U-shaped production line. Eur J Oper Res 145(2):403424

12. Bortolini M, Faccio M, Gamberi M, Pilati F (2017) Multi-objective assembly line balancing considering component picking and ergonomic risk. Comput Ind Eng 112:348-367

13. Finnsgård C, Wänström C (2013) Factors impacting manual picking on assembly lines: an experiment in the automotive industry. Int J Prod Res 51(6):1789-1798
14. Calzavara M, Hanson R, Sgarbossa F, Medbo L, Johansson MI (2017a) Picking from pallet and picking from boxes: a time and ergonomic study. IFAC-PapersOnLine 50(1):6888-6893

15. Salveson ME (1955) J Ind Eng 6(3):18-25

16. Boysen N, Fliedner M, Scholl A (2007) A classification of assembly lie balancing problems. Eur J Oper Res 183(2):674-693

17. Suzaki K (1987) The new manufacturing challenge: techniques for continuous improvement. Free Press, New York

18. Black JT (1991) The design of the factory with a future. McGrawHill, New York

19. Black JT, Hunter SL (2003) Lean manufacturing systems and cell design. Society of Manufacturing Engineers

20. Mileham A, Wang Q, Lassalle S, Owen G (2008) Modelling a walking worker assembly system. In: Proceedings of 18 th international conference on flexible automation and intelligent manufacturing, Skövde, Sweden, 30 June-2 July 2008

21. Bartholdi JJ, Eisenstein DD (2005) Using bucket brigades to migrate from craft manufacturing to assembly lines. Manuf Serv Oper Manag 7(2):121-129

22. Azzam SR, Arias LC, Zhou S (2011) Managing a manufacturing system with integration of walking worker and lean thinking. World Acad Sci Eng Technol 79:725-727

23. Deepak A, Srivatsan R, Samsingh V (2017) A case study on implementation of walking worker assembly line to improve productivity and utilisation of resources in a heavy duty manufacturing industry. FME Trans 45(4):496-502

24. Al-Zuheri A, Lee L, Xing K (2010) An integrated design support methodology for walking worker assembly lines. Lecture Notes in Engineering and Computer Science, $\mathrm{p} 2182$

25. Al-Zuheri A, Luong L, Xing K (2012) The role of randomness of a manual assembly line with walking workers on model validation. Procedia CIRP 3:233-238

26. Al-Zuheri A, Luong L, Xing K (2013) Prediction and analysis impact of operational design of a manual assembly system with walking workers on performance. Int J Comput Integr Manuf 26(6):540-560

27. Al-Zuheri A, Luong L, Xing K (2014) Using simulation in verification of a mathematical model for predicting the performance of manual assembly line occupied with flexible workforce. Int J Simul Process Model 9(4):270-284

28. Amini Malaki A (2012) A study of the effects of operational time variability in assembly lines with linear walking workers (Dissertation). Retrieved from http://urn.kb.se/resolve?urn=urn: nbn:se:hj:diva-17877

29. Sriram S, Kuhl ME, Thorn BK, Carrano AL (2014) A novel worksharing protocol for U-shaped assembly lines. In: Proceedings of the Winter Simulation Conference 2014, Savanah, GA, pp 21132123. https://doi.org/10.1109/WSC.2014.7020056

30. Al-Zuheri A, Xing K, Luong L (2013) Mathematical modelling for process design of walking worker assembly line in productivity and ergonomics perspectives. Int J Ind Syst Eng 14(1):104-137

31. Cevikcan E (2016) An optimization methodology for multi model walking-worker assembly systems: an application from busbar energy distribution systems. Assem Autom 36(4):439-459

32. Bartholdi JJ, John J, Eisenstein DD, Lim YF (2007) Chaos and convergence on bucket brigade assembly lines. Manufacturing and Service Operations Management Society (MSOM) Conference. Available at: http://ink.library.smu.edu.sg/lkcsb research $/ 2420$

33. Bractu AI, Dolgui A (2009) Some new results on the analysis and simulation of bucket brigades (self-balancing production lines). Int J Prod Res 47:369-387

34. Gurumoorthy KS, Banerjee A, Paul A (2009) Dynamics of 2worker bucket brigade assembly line with blocking and instantaneous walk-back. Oper Res Lett 37:159-162 
35. Lassalle S, Wang Q, Owen GW, Mileham AR (2007) A study of inprocess waiting time on a linear walking worker assembly line. $\mathrm{J}$ Eng Manuf 221:1763-1770

36. Wang Q, Lassalle S, Mileham AR, Owen GW (2009) Analysis of a linear walking worker line using a combination of computer simulation and mathematical modeling approaches. J Manuf Syst 28:64 70

37. Wang Q, Lassalle S, Mileham AR, Owen GW (2010) Analysis of production loss on a linear walking worker line. Int Sch Sci Res Innov 4(5):608-612

38. Wang Q, Owen GW, Mileham AR (2007) Determining numbers of workstations and operators for a linear walking-worker assembly line. Int J Comput Integr Manuf 20:1-10

39. Cevikcan E (2014) A mathematical programming approach for walking-worker assembly systems. Assem Autom 34(1) 17104128:56-68

40. Şahin M, Kellegöz T (2019) Balancing multi-manned assembly lines with walking workers: problem definition, mathematical formulation, and an electromagnetic field optimisation algorithm. Int $\mathbf{J}$ Prod Res 57(20):6487-6505

41. Schaft T (2013) Lean approach to operations management, Bachelor thesis. Hamburg University of Applied Sciences. https:// reposit.hawhamburg.de/handle/20.500.12738/6187

42. Wang Q, Bennett N (2014) Integration of lean approaches to manage a manual assembly system. Open J Soc Sci 2:226-231

43. Al-Zuheri A, Luong L, Xing K (2014) A framework for the modelling and optimisation of a lean assembly system design with multiple objectives (book Chapter). Smart Manufacturing Innovation and Transformation: Interconnection and Intelligence, pp 96-125

44. bin Che Ani MN, Ismail AB, Mustafa SA, Feng CJ (2013) Simulation analysis of rabbit chase models on a cellular manufacturing system. Appl Mech Mater 315:78-82

45. Al-Zuheri A, Luong L, Xing K (2016) Developing a multiobjective genetic optimisation approach for an operational design of a manual mixed-model assembly line with walking workers. J Intell Manuf 27(5):1049-1065

46. Colombini D, Occhipinti E (2006) Preventing upper limb workrelated musculoskeletal disorders (UL-WMSDS): new approaches in job (re)design and current trends in standardization. Appl Ergon 37(4):441-450

47. Battini D, Calzavara M, Otto A, Sgarbossa F (2017) Preventing ergonomic risks with integrated planning on assembly line balancing and parts feeding. Int J Prod Res 55(24):7452-7472

48. Gunther RE, Johnson GD, Peterson RS (1983) Currently practiced formulations for the assembly line balance problem. J Oper Manag 3:209-221

49. Carnahan BJ, Norman BA, Redfern MS (2001) Incorporating physical demand criteria into assembly line balancing. IIE Trans 33: 875-887

50. Otto A, Scholl A (2011) Incorporating ergonomic risks into assembly line balancing. Eur J Oper Res 212(2):277-286

51. Bautista J, Alfaro-Pozo R, Batalla-García C (2016a) Maximizing comfort in assembly lines with temporal, spatial and ergonomic attributes. Int J Comput Intell Syst 9:788-799

52. Bautista J, Batalla-García C, Alfaro-Pozo R (2016b) Models for assembly line balancing by temporal, spatial and ergonomic risk attributes. Eur J Oper Res 251:814-829

53. Battini D, Delorme X, Dolgui A, Persona A, Sgarbossa F (2016b) Ergonomics in assembly line balancing based on energy expenditure: a multi-objective model. Int J Prod Res 54(3):824-845
54. Dalle Mura M, Dini G (2019) Optimizing ergonomics in assembly lines: a multi objective genetic algorithm. CIRP J Manuf Sci Technol 27:31-45

55. Zhang Z, Tang Q, Ruiz R, Zhang L (2020) Ergonomic risk and cycle time minimization for the U-shaped worker assignment assembly line balancing problem: a multi-objective approach. Comput Oper Res 118:104905

56. Christmansson M, Medbo L, Hansson G, Ohlsson K, Byström J, Möller T, Forsman M (2002) A case study of a principally new way of materials kitting - an evaluation of time consumption and physical workload. Int J Ind Ergon 30(1):49-65

57. Ciriello VM (2003) The effects of box size, frequency and extended horizontal reach on maximum acceptable weights of lifting. Int $\mathrm{J}$ Ind Ergon 32(2):115-120

58. Neumann WP, Medbo L (2010) Ergonomic and technical aspects in the redesign of material supply systems: big boxes vs. narrow bins. Int J Ind Ergon 40(5):541-548

59. Calzavara M, Glock CH, Grosse EH, Persona A, Sgarbossa F (2017) Analysis of economic and ergonomic performance measures of different rack layouts in an order picking warehouse. Comput Ind Eng 111:527-536

60. Hanson R, Medbo L, Assaf M, Jukic P (2018) Time efficiency and physical workload in manual picking from large containers. Int $\mathrm{J}$ Prod Res 56(3):1109-1117

61. Hanson R, Medbo L, Jukic P, Assaf M (2016) Manual picking from large containers-time efficiency and physical workload. IFACPapersOnLine 49(12):1703-1708

62. Backman K (2008) VASA ergonomic requirements. Volvo Corporate Standard STD 8003, 2.

63. Battini D, Calzavara M, Otto A, Sgarbossa F (2016a) The integrated assembly line balancing and parts feeding problem with ergonomics considerations. IFAC-PapersOnLine 49(12):191-196

64. Bautista-Valhondo J, Alfaro-Pozo R (2018) A case study at the Nissan Barcelona factory to minimize the ergonomic risk and its standard deviation in a mixed-model assembly line. Prog Artif Intell 7(4):327-338

65. Finco S, Battini D, Delorme X, Persona A, Sgarbossa F (2020) Workers' rest allowance and smoothing of the workload in assembly lines. Int J Prod Res 58(4):1255-1270

66. Scholl A (1995) Balancing and sequencing of assembly lines. Physica- Verlag, Berlin

67. Garg A, Chaffin DB, Herrin GD (1978) Prediction of metabolic rates for manual materials handling jobs. Am Ind Hyg Assoc J 39(8):661-674

68. Price $\mathrm{AD}$ (1990) Calculating relaxation allowances for construction operatives - part 1: metabolic cost. Appl Ergon 21(4):311-317

69. Glock CH, Grosse EH, Jaber MY, Smunt TL (2019) Novel applications of learning curves in production planning and logistics. Comput Ind Eng 131(May 2019):419-421

70. Finco S, Zennaro I, Battini D, Persona A (2019) Workers' availability definition through the energy expenditure evaluation. Proceedings - 25th ISSAT International Conference on Reliability and Quality in Design, 1-3 August, Las Vegas NV (USA), pp 29 33

71. Bortolini M, Faccio M, Gamberi M, Pilati F (2020) Motion Analysis System (MAS) for production and ergonomics assessment in the manufacturing processes. Comput Ind Eng 139:105485

Publisher's note Springer Nature remains neutral with regard to jurisdictional claims in published maps and institutional affiliations. 